\title{
LA RADIO Y LA TELEVISIÓN EN “APRENDO EN CASA": HALLAZGOS POR CODIFICACIÓN ABIERTA
}

\author{
LUIS-Rolando ALARCón-LLONTOP* \\ Universidad Privada del Norte \\ luis.alarcon@upn.edu.pe \\ KARL TORRES-MIREZ** \\ Universidad César Vallejo \\ ktorresfre@ucvvirtual.edu.pe \\ Sindy PASAPERA-RAMÍREZ*** \\ Universidad Señor de Sipán \\ pramirezsr@crece.uss.edu.pe \\ MiRTha CarRasco-Yovera**** \\ Universidad Nacional de Piura \\ mcarrascoyo@unp.edu.pe
}

RESUMEN. Esta investigación versa sobre lo que significó la estrategia "Aprendo en casa" en el Perú, en el año 2020, desde dos de sus recursos principales: la radio y la televisión. El objetivo fue analizar comunicacionalmente y evaluar los programas de ambos medios. Se discutió sobre treinta y dos piezas de todos los niveles educativos, en un periodo de siete meses, con veintisiete expertos comunicadores y se evaluó la experiencia a partir de cincuenta actores destino de la estrategia. El estudio fue metodológicamente naturalista, de enfoque cualitativo, con tipologías hermenéuticas indirectas y fenomenológicas, y bajo diseño de codificación abierta. Se hallaron ocho categorías generadas a pleno

\footnotetext{
* Doctor en Comunicación Social por la Universidad César Vallejo, Perú (véase: https://orcid.org/0000-00019912-1299).

** Magíster en Administración y Marketing por la Universidad Señor de Sipán, Perú (véase: https://orcid. org/0000-0002-6623-936X).

*** Magíster en Gestión de Empresas Turísticas y Hoteleras por la Universidad Señor de Sipán, Perú (véase: https://orcid.org/0000-0002-8095-2882).

**** Bachiller en Ciencias de la Comunicación por la Universidad Nacional de Piura, Perú (véase: https:// orcid.org/0000-0001-5823-1475)
} 
albedrío que arrojan resultados sobre sesgados contenidos y cuestionables formas de presentación; se visibilizaron brechas educativas, digitales y generacionales, así como desarticulación entre los ejes educación y comunicación. Lo encontrado aspira a contribuir a la mejora del diseño y uso de recursos mediáticos a favor de la incursión educativa analizada y sus similares.

PALABRAS CLAVE: comunicación educativa / educación mediática / radio educativa / televisión educativa / Perú

\section{RADIO AND TELEVISION IN “APRENDO EN CASA”: FINDINGS BY OPEN CODING}

ABSTRACT. This research is about what the "Aprendo en casa" strategy in Peru in 2020 meant from two of its main resources, radio and television. The objective was to analyze communicationally and evaluate the programs of both media. Thirty-two pieces from all educational levels were discussed, in seven months, with 27 expert communicators, and the experience from 50 target actors of the strategy was evaluated. The study was methodologically naturalistic, with a qualitative approach, indirect hermeneutical and phenomenological typologies, and under an open coding design. Eight categories generated by free will were found to show results on biased content and questionable forms of presentation; gaps were made visible at the educational, digital, and generational levels, and disarticulation between the education and communication axes. Our findings will contribute to improve the design and use of media resources in favor of the educational foray analyzed and the like.

KEYWORDS: educational communication / media education / educational radio / educational television / Peru 


\section{RÁDIO E TELEVISÃO EM "EU APRENDO EM CASA": DESCOBERTAS POR CODIFICAÇÃO ABERTA}

RESUMO. Esta pesquisa visa analisar o que significou a estratégia "Eu aprendo em casa", no Peru em 2020, a partir de dois de seus principais recursos: rádio e televisão. 0 objetivo foi analisar e avaliar comunicacionalmente os programas de ambas as mídias. Foram discutidas 32 peças de todos os níveis de ensino, em um período de sete meses, com 27 comunicadores especialistas; também se avaliou a experiência de 50 atores-alvo da estratégia. 0 estudo foi metodologicamente naturalista, com abordagem qualitativa, tipologias hermenêuticas e fenomenológicas indiretas e sob desenho de código aberto. Foram encontradas oito categorias geradas por livre arbítrio que mostram resultados sobre conteúdo tendencioso e formas questionáveis de apresentação; as lacunas tornaram-se visíveis no nível educacional, digital e geracional; bem como a desarticulação entre os eixos educação e comunicação. 0 que foi encontrado visa contribuir para o aprimoramento da concepção e utilização dos recursos midiáticos em prol da incursão educacional analisada e em contextos similares.

PALAVRAS-CHAVE: comunicação educacional / educação para a mídia / rádio educacional / televisão educacional / Peru 


\section{INTRODUCCIÓN}

Muchos países a nivel mundial intentaron frenar los estragos de la pandemia del COVID19 con el aislamiento social obligatorio, lo que llevó al cierre físico de las escuelas desde principios del 2020. De acuerdo con Álvarez et al. (2020), se generó la necesidad de preservar la educación, para lo cual los gobiernos emplearon varias tecnologías de la información y la comunicación (TIC) de emergencia dirigidas a la educación a distancia, acelerando el proceso de digitalización educativa (Frantani, 2021). Básicamente, la educación debía mantener los lineamientos del currículo escolar, planteado previamente para un contexto "normal". Niño et al. (2021) hablan de la velocidad con la que se combinaron soluciones y medios de primera generación: radio, televisión, materiales impresos, así como de segunda generación: plataformas, sistemas de gestión de aprendizaje.

En ese marco, en el Perú se dispuso afrontar el año escolar 2020 con la estrategia "Aprendo en casa", de manera obligatoria para todas las instituciones educativas públicas (Resolución Ministerial 160-2020-MINEDU, 2020). La incursión planteó echar mano de recursos de radio y televisión al amparo de la Ley de Radio y Televisión que apela a la responsabilidad social de los medios; a la búsqueda de satisfacer necesidades de educación de los ciudadanos, en el respeto de derechos y deberes fundamentales; y a demandar a los radiodifusores apoyar en campañas en situaciones de emergencias (Ley 28278, 2004).

Este estudio se origina por encargo del Consejo Consultivo de Radio y Televisión (CONCORTV), órgano autónomo adscrito al Ministerio de Transportes y Comunicaciones del Perú, entre cuyas funciones destaca "propiciar investigaciones académicas que promuevan el mejoramiento de la radio y televisión" (CONCORTV, 2021). El artículo se basa en dicho estudio, siempre con el objetivo de analizar comunicacionalmente y evaluar los programas de radio y televisión de la estrategia "Aprendo en casa", a partir de expertos comunicadores y actores centrales de la experiencia, pero girando su diseño original de uno sistemático y narrativo a otro de codificación abierta, con lo que los datos obtenidos y hallazgos se amplían, precisan y generan nueva y relevante información.

\section{El COVID-19 y respuestas desde lo educativo escolar}

La pandemia del SARS-CoV-2 convocó reacciones en el plano educativo en todas partes. En Reino Unido y España, los docentes requirieron aprender nuevas habilidades para comunicarse y enseñar en línea. El uso de plataformas educativas les ayudó a mejorar capacidades y desempeños, y resultó un reto para educadores y estudiantes. Así, se evidenció la urgencia de mejorar competencias digitales en ambos, lo que para los maestros significó mayor esfuerzo. Nace entonces un nuevo modelo de enseñanza que podría denominarse "en el momento que se necesita", recordando al mundo que el cambio puede ser paulatino, pero también inesperado e incluso shockeante. Y precisamente son 
los educadores los llamados a la innovación, la investigación y el desarrollo, potenciando sus habilidades en conjunto con las de sus estudiantes (Harris, 2021; Santa, 2021).

Hordatt y Haynes (2021) abordan la problemática latinoamericana: con el uso de las TIC se hizo evidente el lento proceso de adaptación de los docentes, pero con la presión de la alfabetización digital por la pandemia tuvieron que aprender de manera acelerada a crear contenidos y usar distintas plataformas. Para Jaramillo (2020), se suman a las dificultades de los docentes y las carencias de sus estudiantes para acceder al aprendizaje en línea las barreras de internet y tecnología, muy comunes incluso para quienes no anticipaban los problemas. La mayoría de los estudiantes experimentaron barreras para su aprendizaje en este contexto: distracciones, mayor ansiedad y menor motivación.

Tanto Lloyd (2020) como Velázquez (2020) coinciden en que a raíz de la pandemia se percibió un incremento de las brechas sociales y digitales en el sistema educativo. En Ecuador se se hicieron patentes, según Balladares (2020), por el poco acceso a internet, la escasa señal, la dificultad de acceder a dispositivos tecnológicos compatibles con las aplicaciones que servían de apoyo a la educación en el modelo b-learning, así como el uso de un solo dispositivo por familia, lo que plantea que la educación virtual es incompatible con algunos sectores poblacionales. Balladares (2020) también aborda la escasa formación tecnológica de los profesores, quienes se convirtieron en tutores virtuales, con esquemas donde prima la comunicación unidireccional.

Otros investigadores han señalado cómo la implementación de las estrategias falló en otros países de la región. En Argentina, Kuz (2021) afirma que no se escatimó experimentar desde lo tecnológico, pero Anderete-Schwal (2020) y Artopoulos (2020) advertían de su ya compleja realidad escolar, la cual se enmarañó más en una atmósfera de miedo que se vio reflejada en el rendimiento estudiantil. En Colombia, el tránsito que supuso el pase de lo físico a lo virtual en su educación escolar causó conflictuaciones entre hogar y escuela, como satirizan algunos de los materiales viralizados en internet que desnudan el sentir de padres y maestros; según Velásquez y Ruidiaz (2021), se desnudó la carga emocional de todos los actores de la educación, en especial en los estudiantes.

\section{El contexto de "Aprendo en casa"}

La estrategia para el Perú denominada "Aprendo en casa", habilitada desde un portal web, se dirigía a cubrir los cinco niveles escolares (inicial, primaria, secundaria, básica especial y básica alternativa) y sus grados desprendidos. La radio y la televisión pública, y algunas emisoras privadas, vía programas temáticos definidos, empezaron a transmitir el programa para los tres primeros niveles; los dos restantes solo se difundían por la radio, aunque unos meses después la televisión se sumó progresivamente. Radio y televisión se combinaban con otros recursos digitales, dispuestos en conjunto por la estrategia (Ministerio de Educación [Minedu], 2020). 
La incursión se erigía en un contexto en el que, en el papel, se pone de relieve una reforma educativa cuyos documentos rectores son la Ley 29944, Ley de Reforma Magisterial, norma vigente desde el 2012 y que enfatiza el papel de los maestros en los espacios pedagógicos, instituye una línea de carrrera meritocrática y regula la evaluación docente (Ley 29944, 2012); el Currículo Nacional, que desde el 2017 se dirige a siete enfoques trasnversales y treinta y un competencias para el perfil del egresado (“Evaluación por competencias", 2019); y el Proyecto Educativo Nacional, vigente desde el 2020, que apela al rol de los medios como impulsores del cambio educativo necesario para el país (Consejo Nacional de Educación [CNE], 2020).

La estrategia se implementaba en un país complejo, diverso y de diferentes matices culturales, como se admite desde el Estado (Gushiken y Campos, 2015), en el que si bien los ciudadanos se reconocen dentro de un variopinto crisol de razas (Instituto Nacional de Estadística e Informática [INEI], 2017), subsiste un marcado racismo que se evidencia en manifestaciones de exclusión y transgresión de libertades y derechos (Ministerio de Cultura, 2017), y que como reflejo tiene a las zonas rurales, indígenas y pobres sufriendo tradicionalmente, en el campo educativo - pero no solo en el sector-, los estragos de una virtual desatención (Defensoría del Pueblo, 2007). Como han listado Cordero et al. (2007), la escasez de caminos accesibles, el transporte público corto, las limitaciones en servicios básicos, la oferta educativa rural con menos horas impartidas en relación con las brindadas en las ciudades no encalla en una educación con la calidad esperada. Salud con Lupa (2020) ha revelado que, de cada diez escuelas rurales, nueve imparten clases en modalidad multigrado o unidocente y casi en esa misma proporción lo hacen sobre infraestructura precaria y sin tecnología.

Y hay más sobre este panorama de desigualdades educativas: los indicadores nacionales sobre tenencia de tecnologías en lo educacional son alarmantes; para ocho alumnos de nivel primario se cuenta con una sola computadora, cifra que mejora a seis alumnos por una comutadora en el nivel secundario, además de que más de la mitad de los profesores carecen de habilidades en el uso de TIC ("Minedu adquirirá más de 840000 tablets para escolares y profesores", 2020); agreguemos a esto el acceso a internet, que es de los más bajos de la región: solo cuatro de cada diez hogares urbanos, lo que recrudece si pasamos al ámbito rural (INEl, 2020), y que en todo caso mejora en promedios para tecnologías más tradicionales: el $100 \%$ de hogares posee un televisor y algo más de nueve de cada 10 una radio (CONCORTV, 2019).

\section{Comunicación educativa, TIC y aprendizajes}

Ortiz Torres (2012) sostiene que la relación entre educación y comunicación se evidencia en los procesos de enseñanza-aprendizaje en los que profesor y estudiante emplean comunicación. Conforme ha ido avanzando la pedagogía se han constituido los conocimientos adquiridos por los seres humanos, los cuales han sido transmitidos por 
los maestros vía comunicación. Se ha visto la evolución de la comunicación educativa que en un inicio fue unidireccional, para luego convertirse en discursiva, empleando el diálogo como herramienta básica. Hoy la comunicación educativa es una función de la pedagogía que no es exclusiva para el intercambio de conocimiento: comparte saberes, expresa sentimientos (de modo oral, escrito, con comunicación no verbal) en los procesos de aprendizaje, etcétera.

En la comunicación educativa las TIC se usan como apoyo fundamental dentro de la educación para optimizar aprendizajes. Ruiz-Velasco (2012) afirma que estas tecnologías cuentan con modelos educativos delineados sobre los cuales se elaboran contenidos digitales y ayudan a mejorar los procesos de aprendizaje. Igualmente, Komal (2018) muestra cómo el escenario educativo ha cambiado drásticamente basándose en la incorporación de la educación electrónica y la globalización. Se estima que la educación centrada en el uso de tecnologías ha motivado a la población a educarse; sin embargo, surge la interrogante sobre si estas son suficientes u óptimas para garantizar el aprendizaje.

Para Peñalosa y Espinosa (2011), la comunicación educativa ha estado vinculada al uso de los medios, tanto para la educación presencial como para la virtual. De allí nace la educomunicación: oral-ritual, icónico-narrativa y alfabético-argumentativa (paradigmática). Ahora bien, Narváez-Montoya (2019) propone a la educomunicación como la totalidad de la subjetivación humana, entendida como la adquisición de diferentes códigos, entre ellos, la lengua particular y la educación mediática como la asunción de los códigos mediáticos, entendidos no como tecnologías, sino como cultura.

\section{Mediatización de la educación}

La mediatización es el proceso por el cual las prácticas cotidianas y las relaciones sociales se forman históricamente en función de los medios de comunicación, de acuerdo con lo indicado por Livingstone (2009). Con base en esta afirmación, hay dos aspectos en los que las fuentes consultadas abordan su conceptualización. En el primero, se apela a la creciente interacción entre los campos educacionales y mediáticos; es así como Jones (2007) afirma que en la estructura global de la educación los medios desempeñan un papel crucial para promover políticas educacionales que tienden a la privatización y la desregulación como parte de una sociedad neoliberal. Ball y Junemann (2012) argumentan que a través de la mediatización de la educación los medios actúan en diversos contextos en los que rechazan y promueven distintos valores educativos. Para Huergo (2001), la educación mediática deja de ser un asunto netamente pedagógico, donde los medios tienen un papel en la forma de ver el mundo y la adquisición de valores.

En el segundo aspecto, la educación mediatizada se define como un conjunto de procesos de aprendizaje y enseñanza que son mediados por las TIC, las cuales se enlazan a los procesos educativos; en tal caso, Marín (2015) indica que persiste el pensamiento 
que asocia la educación mediatizada a la inserción de los medios y las TIC como aspectos claves para asegurar la innovación educativa que incluye a estudiantes y docentes; este pensamiento es una utopía en la región latinoamericana, puesto que si nos basamos en él, no existirían las brechas educativas relacionadas con las tecnologías de la información y la comunicación.

Existe una postura distinta de las dos anteriores sobre mediatizar la educación, donde esta se convierte en una acción que se asocia con los procesos de mediación entre más de dos elementos, lo que quiere decir mediatizar la proximidad a una cosa. Así, Gutiérrez y Prieto (2007) afirman que mediatizar la educación no precisamente hace referencia al uso de una computadora, el proyector multimedia, un aparato de televisión o de cualquier otro medio de comunicación que conocemos hoy. Reforzando esta postura, Marín (2015) considera que en la educación también juegan como medios los libros, la pizarra y el bloc de notas, por ejemplo. En muchos casos no se requiere de estos para decir que la educación se ha mediatizado; son suficientes las gestualidades y oralidad de los docentes y estudiantes como medios para generar procesos educativos, los cuales son el objetivo de mediatizar la educación.

\section{Televisión y radio educativa}

Se afirma que la función social de la televisión es, a nivel global, la de promover y cultivar tanto valores como cultura. En esa línea, Abrego (2000) indica que la televisión no tiene por obligación educar a sus televidentes; sin embargo, hay especialistas en educomunicación como Kaplún (al cual el mismo Abrego hace referencia) que afirman que todos los programas son educadores; pero - tal cual sucede en las escuelas o en los hogares- se puede educar bien o mal. Del mismo modo, Repoll (2010) mantiene la postura que sostiene la innegable influencia de la televisión como un medio de comunicación que mueve masas y cuyos contenidos y efectos no son necesariamente educativos. Sobre esto, Fernández (2008) considera que en diversos países los medios audiovisuales son inapropiados en su programación, y hay carencia de catálogos informativos, que se puedan adaptar para la enseñanza, a lo que se suma lo costosa que suele ser la televisión educativa. Y aún se espera que se establezcan lineamientos claves que vinculen los contenidos televisivos a la pedagogía y la didáctica.

Para Merayo (2000), conceptualizar a la radio educativa puede ser complejo. La radio desde sus inicios fue promotora de movimientos sociales transgresores. Hermosín-Mojeda y Mora-Jaureguialde (2019) describen cómo se convirtió en extensión y complemento de la educación formal para quienes vivían en zonas donde las instituciones educativas no tenían asientos físicos. La radio es un punto central del discurso popular como medio de transmisión política, social, educativa y de protesta, con la intención de movilidad física e intelectual. Por otra parte, Mora-Jaureguialde (2016) expresa que es básico que la radio, para ser considerada educativa, se caracterice por tener 
objetivos no comerciales y orientación a metas sociales. En cuanto al proceso de cambio experimentado por la radio, Magnoni y Rodrigues (2013) sostienen que esta se ha adaptado a las evoluciones tecnológicas; se ha incluido la incorporación de varios dispositivos en una sola plataforma, dinamizando la interacción de oyente-radio a través de las herramientas que provee internet. Académicos entrevistados por Teixeira et al. (2018) afirman que la radio educativa ha migrado a la web 2.0 como parte de la innovación mediática que eliminará las distancias geográficas de la educación y promoverá la producción innovadora en formas de interacción.

\section{METODOLOGÍA}

Este estudio sentó sus bases en el paradigma naturalista, pues se erigió desde lo interpretativo y nuestra percepción fundamentada como investigadores (Apolaya Sotelo, 2015); así como en el enfoque cualitativo, abierto y racionalmente válido para asir una variable de naturaleza difícil, inmensurable (Benites Romero y Villanueva López, 2015). Todo ello con el fin de analizar y comprender datos para responder a interrogantes hacia nuevos saberes (Hernández Sampieri et al., 2014). Se hizo hincapié en los tipos hermenéuticos y fenomenológicos: por un lado, se ahondó en puntos de vista semánticos y pragmáticos procurando profundidad analítica; $y$, por otra parte, se evaluó el fenómeno mismo de estudio desde los propios actores o sujetos activos, tal y como lo experimentan, viven y perciben (Martínez Miguélez, 2009, sobre las bases respectivas de Navarro y Díaz, 1998; y Husserl, 1962).

La tipología hermenéutica sirvió para el análisis comunicacional de las piezas de radio y televisión de la estrategia "Aprendo en casa", pero no directamente, sino a través de expertos que evaluaron los recursos, en diálogo con los investigadores, con una guía de preguntas sobre precategorías. La tipología fenomenológica se usó para la evaluación cualitativa de los recursos de radio y televisión de la incursión, teniendo como informantes/participantes a los mismos actores centrales de la estrategia, en quienes se buscó testimonio de sus vivencias directas con el objeto de estudio.

El diseño se enmarca en la codificación abierta, uno de los prodecimientos y propuestas válidas para la teoría fundamentada, como ha sintetizado Monge Acuña (2015) sobre Strauss y Corbin de 1994 y Saldaña del 2009 (quien resume a Strauss y Glaser de 1967). "Este tipo de codificación se basa en establecer categorías a pleno albedrío, prioriza la producción de todas las categorías que se generen" (Benites Romero y Villanueva López, 2015, p. 138).

Se contó con tres universos informantes. El principal (directo, objeto mismo de estudio) estuvo conformado por los programas de radio y televisión de la estrategia emitidos entre el 6 de abril y el 30 de octubre del 2020; comprendían cinco niveles educativos: inicial, primaria, secundaria, básica especial y básica alternativa; y se dirigían a materias específicas. El segundo universo (de tipo indirecto o primer grupo de discusión) 
estaba formado por comunicadores expertos en radio y televisión, docentes de universidades peruanas, cuya principal cualidad fue el dominio de temáticas y práctica en los medios estudiados, por lo que sus miradas en diálogo resultaban enriquecedoras. El tercer universo (indirecto e igualmente segundo grupo de discusión) estuvo constituido por actores centrales de la estrategia: directores, docentes, padres de familia y estudiantes; todos presentaban la cualidad de vivir directamente la experiencia y, por tanto, podían evaluarla como sujetos-destino.

Para el primer universo de informantes, los programas de radio y televisión de "Aprendo en casa", la muestra se obtuvo al azar vía muestreo sistemático o por método de intervalos hasta completar cuotas espaciando la elección durante los siete meses de estudio de la incursión. Este muestreo fue probabilístico. Los criterios de inclusión incidieron en todos los niveles de enseñanza que estarían representados y solo en programas dispuestos en la plataforma de la estrategia. Y los criterios de exclusión, sobre programas repetidos y con fallas técnicas. Se fijaron treinta y dos programas en total, considerando cuatro por medio y ocho por nivel, con excepción de dos niveles en los que solamente se habían implementado programas de radio.

Para el universo de informantes comunicadores especialistas (profesores universitarios de radio y televisión), la muestra fue por conveniencia, según el método de sujetos colaboradores hasta completar cuotas, que superamos: veintisiete docentes, al menos dos especialistas de radio o televisión por nivel educativo de los programas analizados. El muestreo fue no probabilístico. Los criterios de inclusión incidieron en docentes de radio o televisión en actividad, quienes debían trabajar en universidades licenciadas y representar casas de estudio de puntos distintos del país. Los criterios de exclusión se fijaron sobre la doble función (por ejemplo, docente universitario y profesor de escuela) o por ser asesor de la estrategia (por conflicto de intereses).

Para el universo de informantes actores centrales de la estrategia, la muestra se seleccionó también por conveniencia con el método de bola de nieve a partir de los sujetos colaboradores hasta completar cuotas. El muestreo fue también no probabilístico. Los criterios de inclusión son los siguientes: actores de zonas urbanas medias de capitales de provincia y distritos, de zonas urbano-marginales y rurales, en menor proporción, y proceder de diversas localidades del país. Los criterios de exclusión: actores sin plena actividad (por ejemplo, docentes con descanso médico), estudiantes de educación básica especial (por no poder brindar información directamente). En total se tuvo a cincuenta actores participantes, entre nueve a quince según tipología específica.

La información de primer orden fue recabada, organizada y analizada articulando previamente una matriz de precategorías, subcategorías y rasgos para cada variable construida sobre varios autores. Se combinaron tres técnicas y sus instrumentos: grupos focales con guía de preguntas y fichas de registro dirigidas a comunicadores especialistas 
y actores centrales, entrevistas con guía de preguntas y ficha de registro para completar información en algunos casos de actores centrales, así como análisis documental con ficha de análisis para organizar y analizar los contenidos de los programas y redondear el análisis comunicacional. Grupos focales y entrevistas se aplicaron de manera remota empleando herramientas digitales como Zoom, Google Meet, llamadas telefónicas y WhatsApp, debido al confinamiento obligatorio.

El procedimiento se puede resumir de la siguiente forma: (a) se ubicó a los comunicadores expertos y a los actores centrales por redes de contactos; (b) los programas fueron seleccionados y organizados según niveles y materias; (c) se presentaron a ambos grupos los objetivos del estudio y se coordinaron reuniones virtuales por separado; (d) a los expertos se les encargó visualizar o escuchar las piezas asignadas según nivel educativo; (e) se dialogó con cada grupo sobre la base de un cuestionario de preguntas abiertas dirigidas en correspondencia a una de las variables (análisis comunicacional o evaluación de la experiencia); (f) la información se pasó a matrices organizadas por claves de respuestas coincidentes, ejemplos y aportes, según grupos de discusión; y (g) se generaron resultados, sin un software avanzado, de modo manual en plantillas de Word, que luego permitieron interpretaciones.

Para el caso específico de este artículo, basado en un diseño de codificación abierta, las categorías resultantes se construyeron reconociendo coincidencias, insistencias, redundancias y particularidades tomadas de las respuestas de los dos grupos de discusión participantes prioritariamente, pero también cruzando la propia observación del fenómeno en estudio, incluso más allá del trazo inicial de precategorías planteadas, precisamente el sentido final del diseño asumido. Para ello, acudimos a lectura y relectura de las informaciones sistematizadas, nueva toma de apuntes, diálogo entre los investigadores, trazo de mapas conceptuales y desarrollo narrativo-explicativo de ideas fuerza.

\section{RESULTADOS}

Sobre las piezas analizadas por docentes universitarios expertos en radio y televisión, así como la valoración de la experiencia de parte de los actores centrales destino de la estrategia, se obtuvieron las ocho siguientes categorías en evidente alternancia:

\section{Centralismo en la producción de los recursos mediáticos}

Se identificó predominancia de una realidad capitalina en el material producido para ambos medios, que no adecuaba su oferta temática y ejemplificadora a las pluralidades del resto del país. Los expertos acusaron centralismo desde elementos no verbales, como la vestimenta de los conductores, siempre urbanos, muy "de ciudad", pasando por las escenografías en televisión y las ambientaciones sonoras en radio, hasta llegar en ambos medios al uso de un lenguaje que no incluía términos propios de las zonas 
rurales, y mucho menos en alguna lengua originaria del Perú (y que en el habla común española peruana suelen filtrarse como aportes), dejando al margen, desde la exclusión lingüística, a poblaciones peruanas presentes en minorías como la quechua, la asháninka, la aimara, entre otras.

Dentro de los programas se incluyeron enlatados provenientes de otros países, lo que si bien pudo pasar desapercibido con alumnos de Lima y capitales de regiones, distanció de identificarse a las mayorías de la periferia y del interior del país, que esperaban algo más localista. Con el avance de la producción esto se redujo y se incluyeron piezas acordes a la realidad peruana, sin dejar reduccionismos y estereotipias (en una animación que mostraba a una familia andina, la madre y la hija asumían un rol hogareño, mientras el padre y el hijo trabajaban en el campo; y la escasa inclusión de la Amazonía). En las piezas radiales no se acudió a ritmos regionales como cumbias, huainos, etcétera, que permitieran la asociación de los estudiantes y un aprendizaje más amistoso.

Desde la perspectiva de los actores de la experiencia, este centralismo supuso un problema al momento de adecuar contenidos: el hecho de mostrar realidades distintas y desconextualizadas implicó que se dejara de usar parte de las piezas de la estrategia, y tuvieran que generarse propias. La estandarización de material no iba de acuerdo con los niveles, realidades o necesidades estudiantiles, y recayó en los docentes seleccionar la información y complementar datos para procurar materiales más eficientes. Esto generó que muchas veces las piezas no fueran tomadas como punto de partida para los aprendizajes.

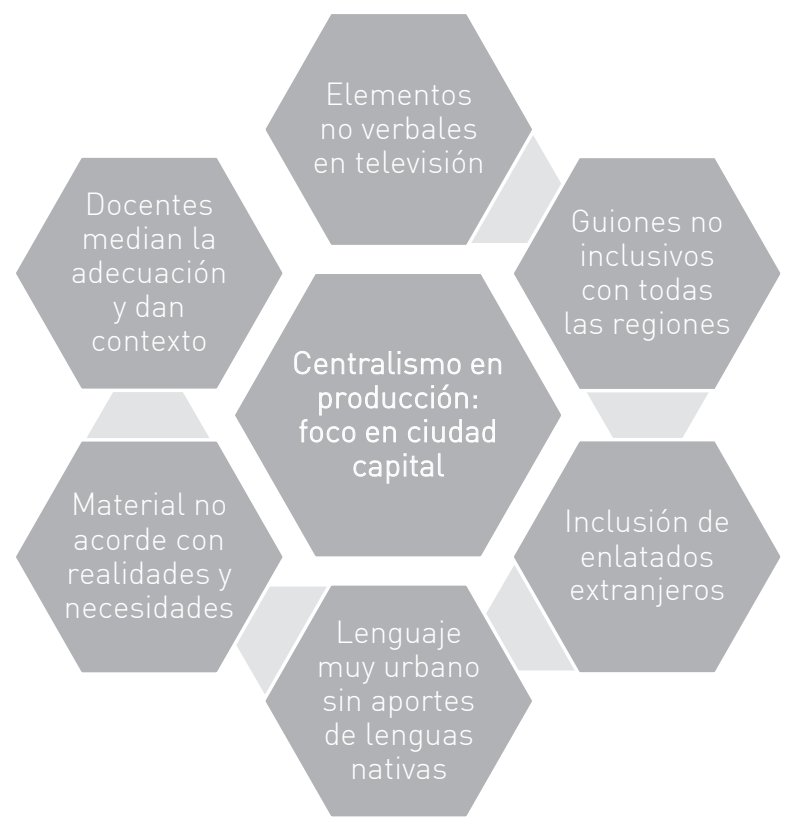

Figura 1. Aspectos del centralismo en la producción de los recursos de radio y televisión Elaboración propia 


\section{Tensión entre las aristas comunicación y educación}

Como experiencia híbrida, la planificación, ejecución y productos de "Aprendo en casa", para su primer año, debía ser el resultado de una armonía educativo-comunicacional. Contrario a ello, se percibió, desde cada parte, que las piezas de radio y televisión abarcaban el punto de vista de uno u otro, pero nunca o muy pocas veces en combinación.

Los comunicadores señalaron que si bien las piezas cumplían un propósito educativo, no reflejaban un orden comunicacional. Acusaban, entre otros puntos, la duración por encima de lo adecuado para el tipo de contenido -30 minutos en televisión y 15 a 20 minutos en radio-, lo que causaba la pérdida de interés de los estudiantes, y el escaso o incorrecto uso de los recursos visuales o sonoros propios del medio, que finalmente no contribuía a la redondez de generar aprendizajes reales.

Contrastando, el tiempo de emisión les resultaba corto a los actores centrales. Docentes y directores coincidían en que algunos cursos y temas abordados requerían más tiempo por el grado de dificultad que representaban, como las de áreas de matemáticas, y ciencia y tecnología. Padres y alumnos pedían que estos tiempos se ampliaran para que pudieran explicarles más y comprender mejor los temas que luego desarrollarían con los docentes, y pondrían en práctica en sus hogares. Los recursos visuales y sonoros de las piezas no fueron percibidos y, por ende, no merecieron comentarios por parte de los actores.

La presentación y los contenidos abordados también fueron materia de discordia. Un punto de polémica recayó en quiénes debían poner cara o voz en las piezas: ¿presentadores de radio o televisión o docentes? Las respuestas coincidían con la profesión de origen de quien comentara. Inicialmente, fueron solo presentadores quienes impartían los conocimientos para la estrategia; tras las críticas, se incluyeron a algunos docentes... parcial migración que no fue del total agrado de los actores centrales-destino, que insistían en que debían ser solo docentes los llamados a definir los productos que finalmente se trazaban como educativos.
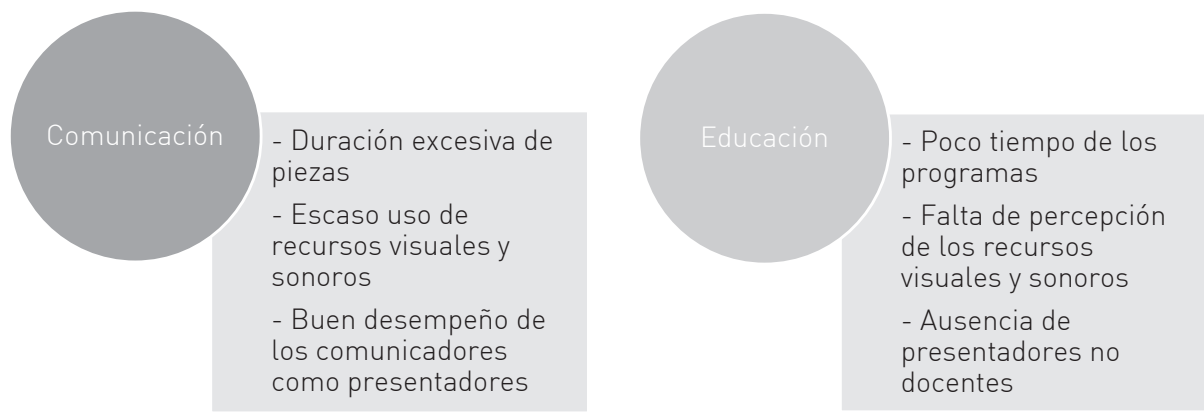

Figura 2. Principales rasgos de la tensión comunicación-educación percibidos

Elaboración propia 


\section{Tradicionalismo en los contenidos de la estrategia}

La producción de los programas de "Aprendo en casa" plasmó y visibilizó paradigmas y estereotipos propios de la sociedad peruana en campos que rebasan lo meramente comunicacional mediático: la verticalidad de las propuestas educativas, los roles de género y la segmentación geográfica-antropológica fueron los principales conceptos tradicionales que, según los expertos, se reforzaron indirectamente.

La escuela tradicional fue llevada del aula a las pantallas con guiones que mostraban la verticalidad del sistema prevaleciente en las escuelas públicas y privadas del Perú, donde el docente cumple el rol de emisor (habla, guía, enseña) y el alumno se limita a su papel de receptor (en pasividad de oyente-cumplidor). El diálogo y, sobre todo, el debate quedaban fuera, inclusive las simulaciones. En este modelo de escuela "cerrada" difícilmente se produce una retroalimentación que pueda evidenciar aprendizajes significativos.

Presencia exclusiva de profesoras en inicial y primaria, con la aparición de un presentador varón para secundaria; animaciones que restringían a las mujeres al hogar y sus labores mientras los hombres salían a trabajar (en el arquetipo de "familia perfecta"); niñas en el rol de alumnas aplicadas que obedecen en todo fueron las principales manifestaciones de estereotipo de género, en clara desventaja para el femenino. Se conminaba a las mujeres a sus espacios-conductas que solo se esperan en sociedades en las que saltos inclusivos de género no se han dado aún.

Finalmente, el centralismo de las piezas - del que ya se habló en su propio apartado-generó una falta de atención al resto de las realidades del país. Las pocas veces que se hizo alusión a estas realidades geográficas (con sus cargas antropológicas propias) se cayó en conceptos repetidos, generando segmentaciones equívocas o parciales de espacios que son más vastos que en el reduccionismo planteado; por ejemplo, ¿en la costa y en la selva peruanas siempre hace calor?, ¿y los Andes son solo fríos?, ¿tal o cual vestimenta típica es la que naturalmente encontratamos en una zona determinada, aun urbana? A modo de procurar una identidad nacional descuidada con esta segmentación geográfico-antropológica, se incluyó en algunas piezas la presencia de Camote, un perro viringo, raza oriunda del Perú. 

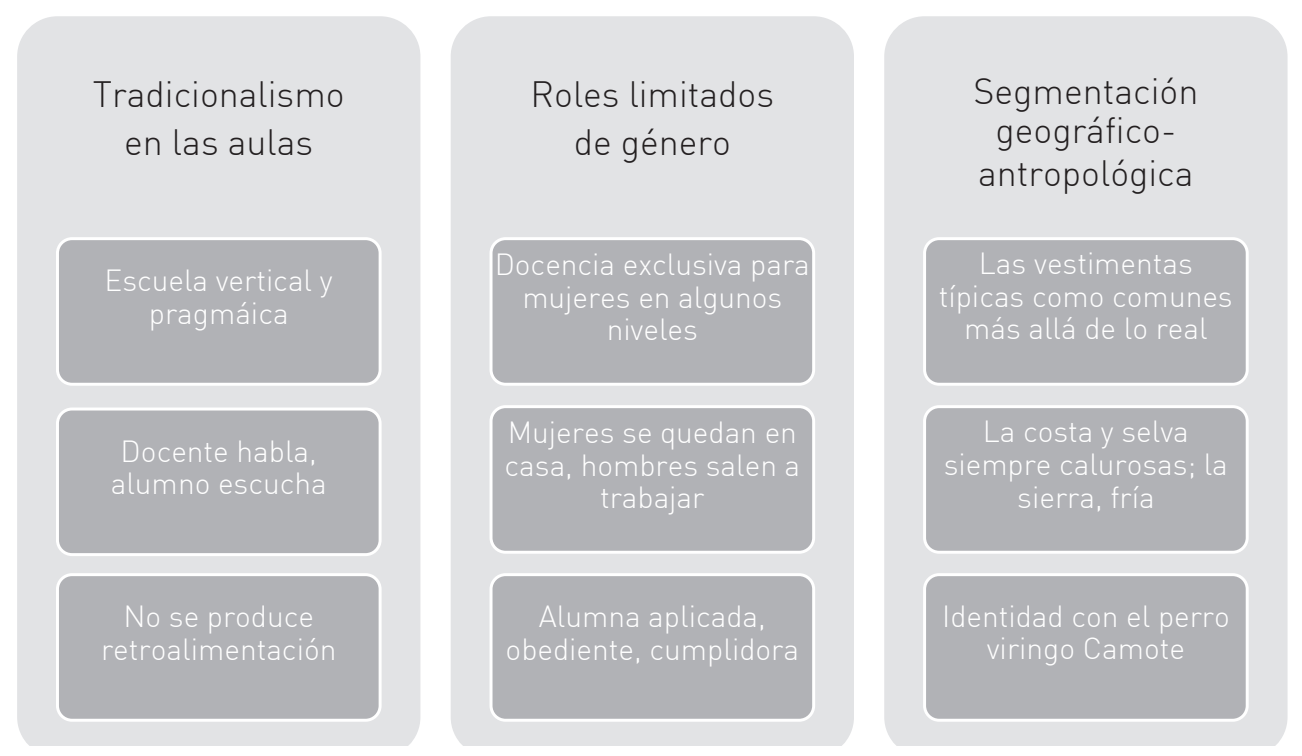

Figura 3. Subcategorías del tradicionalismo en los contenidos de la estrategia

Elaboración propia

\section{Atención dispar a los niveles educativos}

Dentro de la educación básica peruana se segmentan tres niveles con características propias: educación básica regular (EBR), básica especial (EBE) y básica alternativa (EBA). Estas dos últimas resultaron marginadas con respecto a la primera durante el primer año de "Aprendo en casa".

Para la EBA, según directivos y docentes, la educación de tipo semipresencial siempre ha sido una necesidad por el público al que se dirige: adultos que trabajan, atienden sus hogares, etcétera, y que no disponen de mucho tiempo para estudiar ni posibilidades completas de presencialidad. La posibilidad de hacer, al menos parcialmente, remoto el nivel había sido postergada hasta la llegada de la estrategia, orillados por la emergencia. Con todo, la propuesta de la EBA en "Aprendo en casa" no supuso un significativo avance: hubo poco material producido, programas solo para los dos primeros subniveles, lo que condujo a los docentes a crear propios contenidos y a los estudiantes a mostrar cierta insatisfacción.

En el caso de la EBE, ciertamente con cosas más delicadas que entender y atender, el tratamiento no fue focalizado a los distintos tipos de discapacidades de los estudiantes; los programas se limitaban a dar instrucciones a los padres, lo cual hizo que resultaran poco prácticos y repetitivos; esto generó malestar en padres y docentes, quienes dentro 
de las limitaciones encontraron una forma de educar más integralmente introduciendo al estudiante en el núcleo familiar, su principal medio de apoyo.

Coincidentemente, ambos niveles, pese a que los actores sintieron indiferencia y poca escucha cuando trataron de comunicarse con autoridades competentes, lograron establecer sistemas de trabajo que finalmente favorecieron a los estudiantes y no detuvieron su proceso de aprendizaje. El rol principal recayó en los docentes (EBA) y en los padres de familia (EBE).

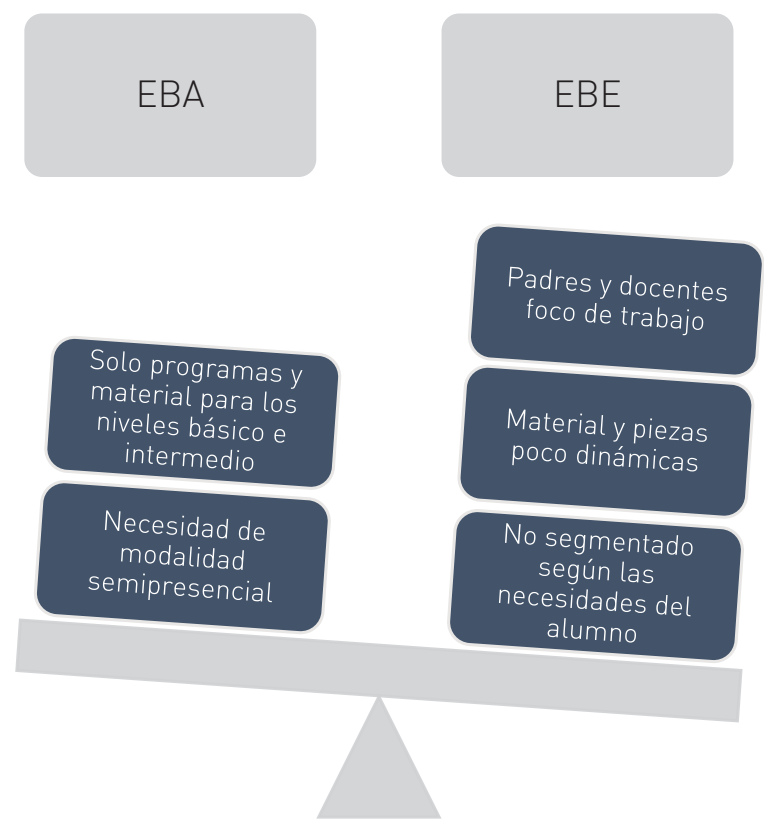

Figura 4. Disparidades en la atención prestada a los niveles educativos

Elaboración propia

\section{Foco en aprendizajes académicos y no emocionales}

La crisis sanitaria por el COVID-19 se tradujo en una incertidumbre respecto del año escolar tras la suspensión de clases y su posterior adecuación totalmente remota en el Perú. Los alumnos, padres, docentes y demás se vieron afectados en distintas esferas de sus vidas, incluyendo la emocional.

Para cumplir con el currículo nacional de aprendizajes, se plantearon las competencias básicas de cada área, las cuales fueron trasladadas hacia piezas de radio y televisión 
desarrolladas posteriomente por los docentes a través de distintos medios tecnológicos. Pero, a pesar de que la enseñanza se ajustaba a lo básico, se llegó a crear un clima de cansancio y saturación que no fue oportunamente abordado por especialistas.

En los estudiantes, el clima inicial fue de emoción y espíritu positivo. Posteriormente cayeron en distracción, cansancio por nuevos métodos de enseñanza-aprendizaje, además de la tristeza y aburrimiento que producía el confinamiento (súmese a esto la preocupación por familiares enfermos, pérdida de trabajo de sus padres, etcétera). Estos aspectos no fueron tratados ni por docentes ni psicólogos de las instituciones, un claro descuido.

Para los docentes, la sobrecarga laboral que convocó el nuevo modelo causó estragos física y emocionalmente. Los padres percibían que eran quienes ahora cumplían la labor de maestros y se registró un número regular de profesores víctimas del COVID-19, lo que retrasó algunas clases. En la versión 2021 de la estrategia se ha buscado abordar el panorama emocional que reclamamos, a través de encuestas; ya se evaluará si resultó acertado.

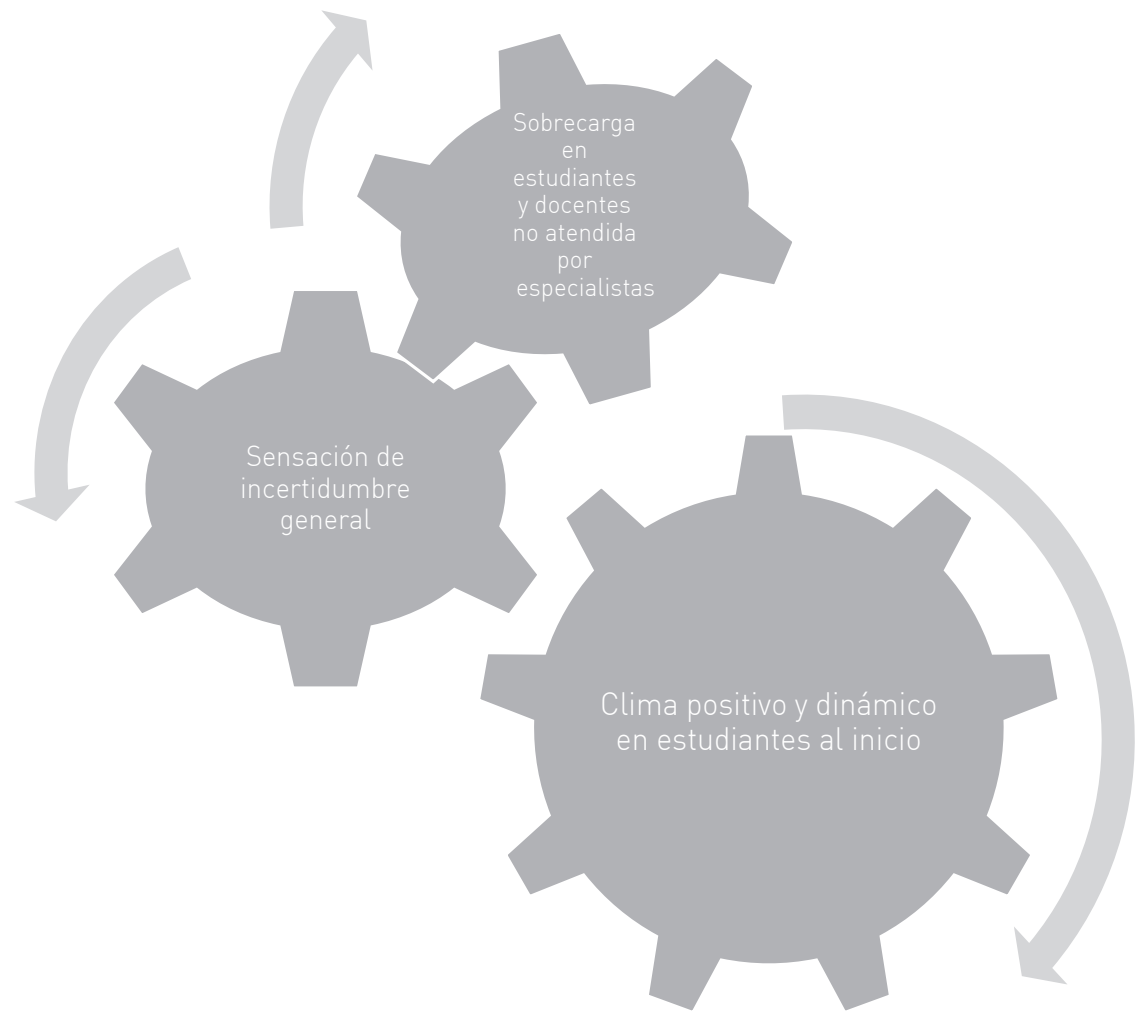

Figura 5. Aspectos del foco en lo académico y no en lo emocional

Elaboración propia 


\section{Amplia brecha digital generacional y geográfica}

La adaptación a la estrategia "Aprendo en casa" supuso un cambio repentino y apresurado en materia de consumo tecnológico en medio de un contexto dispar debido a las variantes geográficas del territorio nacional. Se evidenció más la ya existente brecha de acceso entre las zonas urbanas, las urbano-marginales y las rurales. Las respuestas de los actores al acomodo sobre esas tecnologías tampoco fueron parejas, debido a las distancias generacionales que pusieron de relieve dos grandes tipologías: los estudiantes menores y el resto.

Geográficamente, muchos estudiantes no pudieron hacer uso de todos los recursos de la estrategia por la falta de acceso total o parcial a las plataformas e incluso a energía eléctrica. Se buscaron alternativas para seguir un trabajo de un lado u otro de los circuitos académicos (sea desde los docentes, padres o alumnos). La zona rural fue una de las más afectadas: sin radio o televisión (por la falta de receptores o por el deficiente o nulo tendido del medio), o por carecer de señal en sus celulares, no tener dinero para recargar datos o no poder ir a zonas con cobertura de señal, muchos escolares dejaron de conectarse a los recursos de la incursión, señalaron los docentes.

Los estudiantes de la periferia urbana presentaron limitaciones parecidas incluso en ciudades principales. En muchos casos, la señal de televisión estatal no era buena; por ello no podían sintonizar los programas; similar situación ocurrió con la radio. En el peor de los casos, tampoco contaban con dispositivos adecuados para conectarse. Ante ello, el trabajo se volvió exclusivo de medios como WhatsApp, activado por profesores creativos y proactivos; esta no fue la solución total, pues el consumo de telefonía móvil es parte de una realidad limitada para un buen porcentaje de la población peruana.

Si las limitaciones anteriores ya suponían un problema, la falta de conocimiento y manejo de tecnologías por parte de directivos, docentes, padres (principalmente) y alumnos (minoría, sobre todo los de sector rural) también afectó el éxito de la estrategia. Quienes se adaptaron más rápido fueron los alumnos y docentes jóvenes, por su cercanía etárea para entenderse con las TIC; a los docentes y padres de edad más avanzada les costó entender funcionamientos tecnológicos nuevos; por lo tanto, su aprendizaje fue paulatino y dado desde las mismas circunstancias prácticas. 


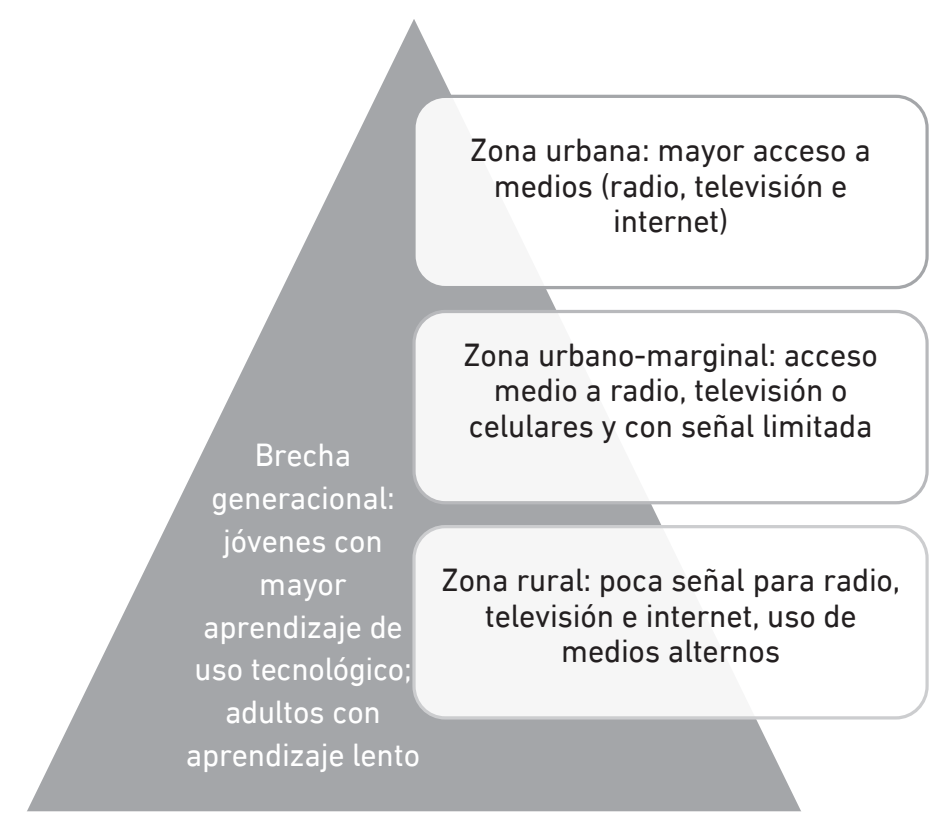

Figura 6. Síntesis de la brecha generacional y geográfica

Elaboración propia

\section{Desarticulación de contenidos según medios}

Como se ha mencionado, la estrategia fue pensada y diseñada para dotar al estudiante de conocimientos básicos respecto de las competencias curriculares; en esa línea, los contenidos fueron desplegados principalmente para las plataformas de radio y televisión, como medios de acceso masivo, y en una plataforma web, que complementaría los medios principales y sería usada como repositorio de información y recursos para los docentes.

En el análisis de las piezas se observó una evolución en cuanto a producción, mas no en la adecuación del contenido educativo. Muchas de las piezas radiales resultaron fiel copia de los guiones televisivos, simplemente trasladados a otra plataforma como repetición, lo que se evidenciaba en el uso de frases propias de la televisión, como "aquí podemos ver", o más aún "en el siguiente video", y en el uso de palabras propias de realidades foráneas como "vos" o "mina". Así, se provocaba confusión en estudiantes y se fomentaba una accidentada comprensión total de los temas, además de no respetar los cánones propios de cada medio.

Se sumó la precariedad y escasez en el uso de recursos que pudieron ser utilizados para enriquecer la narrativa del medio, lo que fue advertido por los especialistas 
comunicadores. Para el caso de EBE, las transmisiones fueron predominantemente descriptivas. En televisión, sin embargo, las imágenes complementaban las indicaciones técnicas dadas, pero al llevar los contenidos a la radio, se perdió el recurso visual y apenas se tuvo como producto un recital de instrucciones.

Si bien la radio y la televisión fueron plataformas principales, la falta de acceso a estos medios en algunas zonas empujó a que los docentes experimentaran alternativas como el uso de WhatsApp, adaptando fichas de trabajo y fragmentos de las piezas centrales, incluso bajo entrega física de material, lo que tuvo que ser pensado para ritmos distintos a los originales de la estrategia. Con esto, aunque se acudió a una suerte de salvavidas para la experiencia, se hizo evidente que no se siguió una relación directa con la planificación nacional, sino que apenas se tuvo una dinámica de solo tomar temáticas y "adecuadarlas" sin las consideraciones de adaptación necesarias.

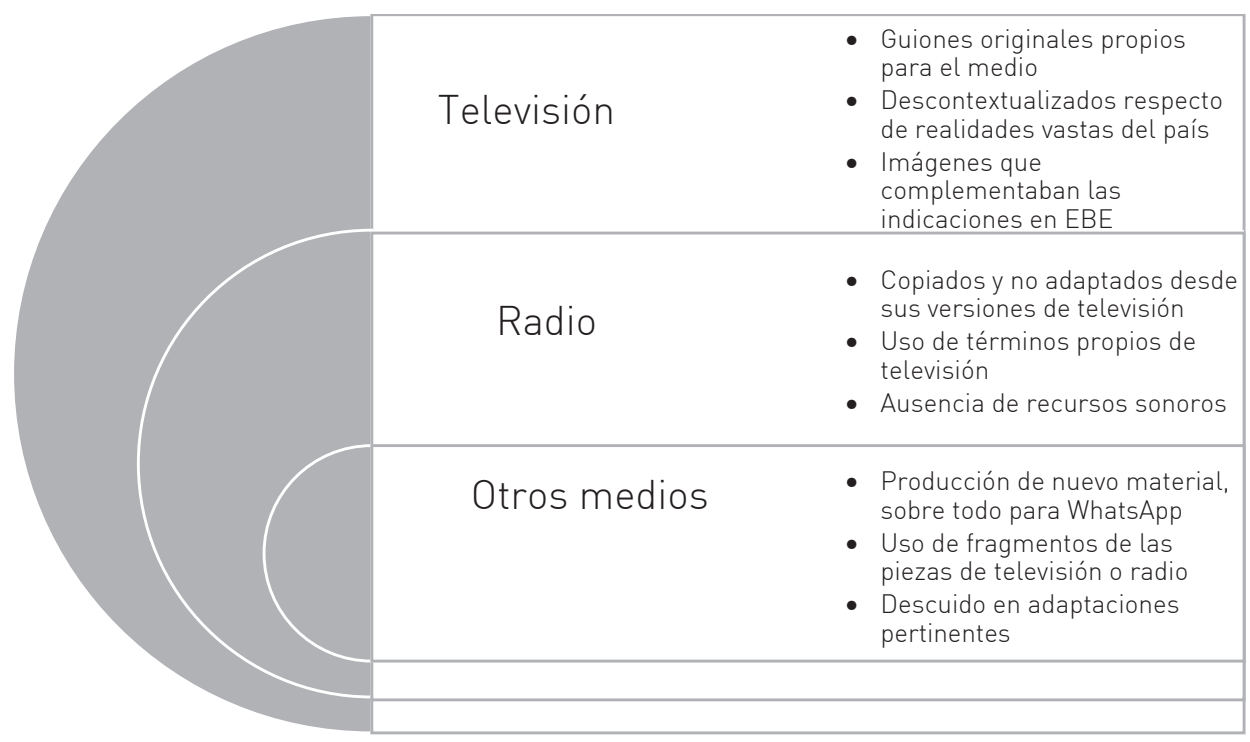

Figura 7. Aspectos de la desarticulación de contenidos según medios

Elaboración propia

\section{Confusión de roles de los actores de la estrategia}

Sobre el rol de los participantes en "Aprendo en casa", se dividieron opiniones sobre cuán claras fueron las funciones que cada quien debía desempeñar en una estrategia que presuponía la articulación de roles-actividades. Principalmente, esta confusión derivó de la falta de comunicación asertiva entre docentes y padres, comunicación que fue predominantemente de maestros a alumnos. 
Los estudiantes fueron quienes entendieron las responsabilidades que conllevaba su rol, algo que no se tradujo necesariamente en el cumplimiento de aquellas a cabalidad. De hecho, señalaron a los docentes como principal fuente de información, más que los padres, por lo que consideraban que eran sus maestros quienes explicaron el sistema de trabajo y evaluación. Muchos de los padres, aun en un papel de mediadores, no coincidían.

Si bien existió comunicación entre padres y maestros, esta fue mayoritariamente escasa. Comunicación que se limitó a una esporádica reunión bimestral a través de Zoom o WhatsApp. Cuando de parte de los padres y madres, en general, se buscaba una comunicación directa con los docentes, era común no recibir respuesta, o no de manera oportuna. La sensación de malestar en muchos padres aumentó. Del lado docente se generó también una percepción de dejadez de los padres hacia los alumnos en cuanto a su rol de acompañantes.

Finalmente, y aunque no fue así desde el inicio, se encontró que la mayor claridad de rol en la estrategia la tuvieron directores y docentes, con matices según nivel educativo. Esto se fue dando con el avance de la estrategia que les permitió entender que se debía transitar hacia un trabajo articulado, de adecuación y seguimiento hacia los estudiantes, y de actualización documentaria frente a las autoridades para el mejor monitoreo de la experiencia.
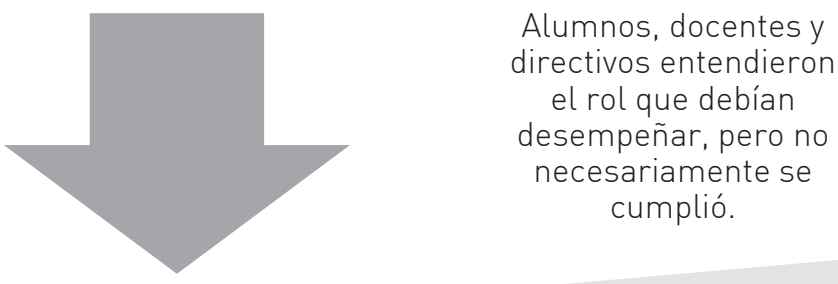
Los padres quedaron confundidos por la
falta de información recibida, hubo percepción de malestar hacia maestros. Y viceversa.

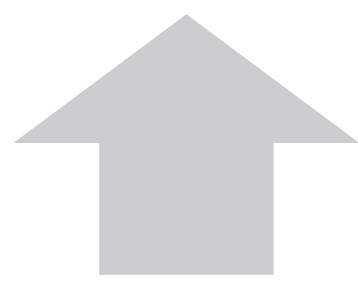

Figura 8. Resumen de la confusión de roles de los actores de la estrategia Elaboración propia 


\section{DISCUSIÓN}

Sobre la primera categoría, "Centralismo en la producción de los recursos mediáticos", y la tercera, "Tradicionalismo en los contenidos", debemos anotar que si bien la premura de la emergencia sanitaria del 2020 obligó a la planificación y ejecución casi instantáneas de un año escolar atípico, la producción de la estrategia empleada se deslindó totalmente de la Ley 28044, Ley General de Educación (2003), que rige en el país y proclama la estructura descentralizada en el sistema educativo de cara a una mejor equidad y mayor participación del interior. Lo que se tuvo fueron producciones con visiones mayoritariamente capitalinas que omitieron las distintas realidades del país, afectando el desarrollo académico de estudiantes y docentes, que generó falta de identificación y quejas en quienes consumían la estrategia.

La escuela peruana mantiene un sistema de carácter conceptualista, que apela a la memorización sobre análisis, en un modelo vertical educativo que contrasta con las nuevas demandas educativas, en clara incoherencia entre discurso, currículo y metodología (Casanova, 2012). Tal rasgo quedó plasmado en las piezas de "Aprendo en casa", con temas estructurados bajo guiones que giraban en torno al docente como único emisor, sin posibilidad de una retroalimentación del estudiante. Por otro lado, la participación específica de niñas en labores de ayuda en casa y mujeres como únicas docentes en niveles de enseñanza inicial y primaria ha reforzado, indirectamente, estereotipos de roles de género, percepción errónea que puede desencadenar dos impactos notables en la educación de la mujer: la deserción escolar y la selección de una carrera futura con base en los estereotipos observados (Ramírez et al., 2019).

Respecto a la cuarta categoría, "Atención dispar a los niveles educativos"; la quinta, "Foco en aprendizajes académicos y no emocionales", y la octava, "Confusión de roles de los actores", es preciso recordar que desde el 2017, con la implementación del Currículo Nacional, la educación peruana se ha propuesto desarrollar treinta y un competencias específicas para formar el perfil idóneo de los estudiantes al término de su educación escolar (“Evaluación por competencias", 2019). Con el objetivo de cumplir con estas competencias a través de las plataformas empleadas en la estrategia, se brindaron las bases teóricas y acompañamiento en esa dirección; pero no se consideró que el brusco cambio, aunado al contexto inestable, generaría saturación en estudiantes, padres y docentes. La ruptura de la cotidianeidad de la vida puede ocasionar el desarrollo de trastornos psicológicos como ansiedad, neurosis, crisis emocionales y depresión (Fernández, 2021). Así, el comportamiento de los actores mencionados experimentó una "montaña rusa" que empezó con expectativa y emoción, pero terminó cayendo en aburrimiento, frustración y dejadez casi al final de la experiencia tanto en padres como en alumnos.

En el sistema educativo se evidencia la prevalencia de discriminación estructural frente a algunos estudiantes, específicamente quienes presentan condición 
de discapacidad, relacionada con el acceso a la educación y otros servicios básicos (Defensoría del Pueblo, 2019). Esta inequidad desfavoreció a los niveles de EBA y EBE, cuyos actores se sintieron marginados al no ser atendidos en contenidos, materiales y recursos tecnológicos dispuestos como en el nivel regular; pese a ello, se formaron entre docentes y padres las bases de una educación integral con adecuación a la realidad propia de cada estudiante. Se revela no uno, sino dos sectores - los escolares adultos y los escolares especiales - como los más desfavorecidos en una educación que, como han reconocido en momentos diferentes Miguel (2005) y Rojas (2014), hemos tenido desde hace mucho de espaldas a aggiornarse y beneficiarse de los aportes de la tecnología, lo que se ha evidenciado en distancias, desaciertos y limitaciones.

Con relación a la sexta categoría, "Amplia brecha digital generacional y geográfica", y la séptima, "Desarticulación de contenidos según medios", debemos incidir que en el Perú la educación ha avanzado de forma desigual en accesos y aprendizajes. De acuerdo con el INEI (2020), si en Lima más del $62 \%$ de los hogares tienen internet y el $52 \%$, una computadora, en el área rural los porcentajes bajan al 5,9\% y 7,5\% respectivamente. Además, solo las tres cuartas partes de hogares rurales tienen radio. Y solo el 51 \% posee un televisor. Si contamos restricciones de señal para ambos medios en lo rural, la estrategia desde sus principales medios no pudo llegar de forma pareja a todos los estudiantes, debiendo buscarse soluciones alternas: adaptación de contenidos, uso de redes sociales en áreas urbano-marginales y algunas rurales, traslado físico de docentes esporádicamente a los centros educativos o casas para repartir material impreso. Además de la brecha geográfica, existe una generacional que deriva en un $55 \%$ de docentes peruanos que no poseen habilidades para usar tecnologías digitales, 69000 docentes carecen de acceso a una computadora y 136000 no cuentan con internet en su hogar, lo cual dificultó su rápida adaptación al trabajo remoto. Nos distanciamos de lo que Angelelli et al. (2020) han reconocido sobre la vinculación de las TIC a lo educativo, que a nivel mundial experimenta gran avance en sus aplicaciones para remontar paradigmas tradicionales.

Y sobre la segunda categoría, "Tensión entre las aristas comunicación y educación", de acuerdo con lo señalado por Ortiz Torres (2012), la comunicación educativa dejó de ser exclusiva para el intercambio de conocimientos o ideas académicas; va más allá para compartir conocimientos, expresar sentimientos haciendo uso de oralidad, escritura y comunicación no verbal en los procesos de aprendizaje, equilibrando una relación que permita su desarrollo. Esto, no obstante, dista de lo percibido en la estrategia, pues no hubo convergencia entre ambos campos para la producción de las piezas; tampoco se generó consenso en cuanto a si el enfoque era correcto, pues un lado acusaba ser una experiencia netamente pedagógica sin manejo comunicacional y el lado de los receptores principales, que son los alumnos, padres y docentes, espetaba lo opuesto: un diseño que olvidaba las bases de la pedagogía. 
Una limitación de la investigación estuvo en su carácter transversal sobre un fenómeno, la estrategia "Aprendo en casa", que se ha movido en muy poco tiempo: ya se tiene a la experiencia en un segundo año lectivo y otra de estas limitaciones puede estar en el exclusivo abordaje desde una perspectiva cualitativa definida, lo que si bien nos permite lecturas interpretativas válidas, estas necesitan complementarse con datos e información procedentes de otros enfoques metodológicos como el cuantitativo y el mixto. Futuras investigaciones podrían asumir ese reto, incluso ampliando la cobertura de medios analizados de la estrategia (por ejemplo, la plataforma web), así como también el rango de los actores-destino (por citar, los directores de las unidades de gestión local [UGEL], los alumnos de básica especial, y participantes de zonas rurales profundas: altoandinas y amazónicas), con técnicas e instrumentos creativos específicos aún por explorar, con el propósito de seguir indagando en la relación de comunicación y educación en la citada experiencia y en otras parecidas.

\section{REFERENCIAS}

Abrego, S. (2000). El guion para televisión educativa formal. El caso de telesecundaria [Tesis de licenciatura no publicada]. Universidad Nacional Autónoma de México.

Álvarez, M., Arias, E., Rieble-Aubourg, S., Rivera, C., Viteri, A., López, A., Pérez, M., Vásquez, M., Bergamaschi, A., Noli, A., Ortiz, M., y Scannone, R. (2020). Education in Times of Coronavirus: Latin America and the Caribbean Education Systems in the Face of COVID-19. Inter-American Development Bank. http://dx.doi. org/10.18235/0002337

Anderete-Schwal, M. (2020). Las desigualdades educativas durante la pandemia en la educación primaria de Argentina. Revista Andina de Educación, 4(1), 5-10. https:// doi.org/10.32719/26312816.2021.4.1.1

Angelelli, P., Hennessey, M., y Henriquez, P. (2020). Respuestas al COVID-19 desde la ciencia, la innovación y el desarrollo productivo. BID. http://dx.doi.org/10.18235/0002347

Apolaya Sotelo, J. (2015). Diseño de investigación del proyecto de investigación (apuntes de curso de Doctorado en Comunicación Social). Escuela de Posgrado de la Universidad César Vallejo.

Artopoulos, A. (2020). COVID-19: ¿Qué hicieron los países para continuar con la educación a distancia? Revista Latinoamericana de Educación Comparada, 17, 1-11. https://bit. ly/3sxA2Ws

Ball, S. J., y Junemann, C. (2012). Networks, New Governance and Education. The Policy Press. 
Balladares, J. (25 de octubre del 2020). Repensar la educación en tiempos de COVID-19. The Conversation. https://bit.ly/35cOgCb

Benites Romero, S. H., y Villanueva López, L. (2015). Retroceder investigando ¡nunca! Rendirse con la tesis ijamás! Metodología de la investigación en Comunicación Social. Fondo Editorial de Cultura Peruana.

Casanova, M. A. (2012). El diseño curricular como factor de calidad educativa. REICE. Revista Iberoamericana sobre Calidad, Eficacia y Cambio en Educación, 10(4), 5-20. https://bit.ly/3wfRaSG

Consejo Consultivo de Radio y Televisión. (2019). Estudio cuantitativo sobre consumo televisivo y radial en adultos. https://bit.ly/2RUiFT2

Consejo Consultivo de Radio y Televisión. (2021). ¿Qué es el CONCORTV? https://bit. ly/3vdycLa

Consejo Nacional de Educación. (2020). Proyecto Educativo Nacional al 2036: el reto de la ciudadanía plena. https://bit.ly/3cEdPk1

Cordero, G., Ames, P., y García, J. (2007). Hacer el conocimiento escolar público: una investigación sobre los procesos de formación docente y el desarrollo de la escuela rural. https://bit.ly/3zga6CG

Defensoría del Pueblo. (2007). La discriminación en el Perú: problemática, normatividad y tareas pendientes. https://bit.ly/3zp6hva

Defensoría del Pueblo. (2019). El derecho a la educación inclusiva. Barreras en la implementación de los servicios públicos y privados para estudiantes con discapacidad y otras necesidades educativas. Informe Defensorial N. ${ }^{\circ} 183$. Biblioteca Nacional del Perú. https://bit.ly/3vjKoKj

Evaluación por competencias [Editorial]. (8 de febrero del 2019). Diario oficial El Peruano. https://bit.ly/3izJnLp

Fernández, G. (2008). TV educativa y profesorado: ¿una relación imposible? Comunicar, 16(31), 593-598. https://doi.org/10.3916/c31-2008-03-055

Fernández, A. M. (2021). 2020: estudiantes, emociones, salud mental y pandemia. Revista Andina de Educación, 4(1), 23-29. https://bit.ly/3pPpphg

Frantani, F. (2021). The Acceleration of Digitalisation within Education as a Result of COVID19. Global Focus: The EFMD Business Magazine, 15(1), 1-4. https://bit.ly/3xi6f6p

Gushiken, R., y Campos, M. A. (2015). Línea de base de brechas sociales por origen étnico en el Perú. Ministerio de Cultura. https://centroderecursos.cultura.pe/es/ 
registrobibliografico/l\%C3\%ADnea-de-base-de-brechas-sociales-por-origen\%C3\%A9tnico-en-el-per\%C3\%BA

Gutiérrez, F., y Prieto, D. (2007). La mediación pedagógica. La Crujía.

Harris, C. (2021). The Role of 'Rich Tasks' an Interdisciplinary and Digital Approach to Learning post COVID-19. Pixel-Bit. Revista de Medios y Educación, 61, 99-130. https://doi.org/10.12795/pixelbit.88209

Hermosín-Mojeda, M. J., y Mora-Jaureguialde, B. (2019). "Radioenseñanza” an Educational Experience for Adults through Radio in Huelva at the End of Francoism. Social and Education History, 8(2), 170-196. https://doi.org/10.17583/hse.2019.3899

Hernández Sampieri, R., Fernández-Collado, C., y Baptista, L. (2014). Metodología de la investigación. McGraw-Hill.

Hordatt, C., y Haynes, T. (2021). Latin American and Caribbean Teachers' Transition to Online Teaching During the COVID-19 Pandemic: Challenges, Changes and Lessons Learned. Pixel-Bit. Revista de Medios y Educación, 61, 131-163. https:// doi.org/10.12795/pixelbit.88054

Huergo, J. (2001). Comunicación y educación. Ámbitos, prácticas y perspectivas. Ediciones de Periodismo y Comunicación; Universidad Nacional de La Plata.

Instituto Nacional de Estadística e Informática. (2017). INEI difunde Base de Datos de los Censos Nacionales 2017 y el Perfil Sociodemográfico del Perú. https://bit. ly/2TUyqtC

Instituto Nacional de Estadística e Informática. (2020). Estadísticas de las Tecnologías de Información y Comunicación en los Hogares [Informe técnico n. 2]. https://bit. ly/3iEkSNm

Jaramillo, S. (9 de octubre del 2020). COVID-19 and Primary and Secondary Education: The Impact of the Crisisand Public Policy Implications for Latin America and the Caribbean. United Nations Development Programme. https://bit.ly/3dLh Jlt

Jones, P. W. (2007). Education and World Order. Comparative Education, 43(3), 325-337. https://www.tandfonline.com/doi/abs/10.1080/03050060701556273

Komal, S. (2018). Online Media for Higher Education: Contributions of Consortium for Educational Communication in India. Global Media Journal: Indian Edition, 10(1), 1-3. https://bit.ly/3pNwX4p

Kuz, A. (2021). Opinions of High School Students and a Teacher in Teaching and Learning during Confinement by COVID-19. Revista Interuniversitaria de Investigación en Tecnología Educativa, 10, 76-90. https://doi.org/10.6018/riite.4644 
Ley 28278. Ley de Radio y Televisión del Perú. 16 de julio del 2004. Normas Legales n. ${ }^{\circ}$ 8791. Diario oficial El Peruano. https://bit.ly/3iLr5H4

Ley 28044. Ley General de Educación. 29 de julio del 2003. Normas Legales n. ${ }^{\circ}$ 8437. Diario oficial El Peruano. https://busquedas.elperuano.pe/download/ full/5nadz0K04GTASaRAXsfYTI

Ley 29944. Ley de Reforma Magisterial. 25 de noviembre del 2012. Normas Legales n. 12271. Diario oficial El Peruano. https://busquedas.elperuano.pe/download/full/ F5fwoJcWq1L98PboURNI7L

Livingstone, S. (2009). On the Mediation of Everything: ICA Presidential Address 2008. Journal of Communication, 59(1), 1-18. https://doi.org/10.1111/j.1460-2466.20 08.01401.x

Lloyd, M. (2020). Desigualdades educativas y la brecha digital en tiempos de COVID-19. En H. Casanova Cardiel (Coord.), Educación y pandemia: una visión académica (pp. 115-121). Universidad Nacional Autónoma de México, Instituto de Investigaciones sobre la Universidad y la Educación. https://bit.ly/3iDReb5

Magnoni, A. F., y Rodrigues, K. (2013). 0 rádio e a adaptação à nova era das tecnologias da comunicação e informação: contextos, produção e consumo. 9. Encontro Nacional de História da Mídia UFOP, Minas Gerais, Brasil. https://bit.ly/3gku1sT

Marín, D. (2015). La educación mediatizada. Distancias y aproximaciones conceptuales en las metodologías de mediatización del conocimiento. Revista da FAEEBA, 44(24), 41-53. https://bit.ly/3hQAfRX

Martínez Miguélez, M. (2009). Ciencia y arte en la metodología cualitativa. Trillas.

Merayo, A. (2000). Identidad, sentido y uso de la radio educativa. En G. Pastor Ramos, M. R. Pinto Lobo, A. L. Echeverri González (Coords.), Cultura y medios de comunicación: actas del III Congreso Internacional, Salamanca, del 15 al 18 de febrero de 1999 (pp. 387-404). Ediciones de la Universidad Pontificia.

Miguel, C. de. (2005). Criterios de innovación para la integración curricular de las tecnologías de la información y la comunicación en el aula. REICE. Revista Iberoamericana sobre Calidad, Eficacia y Cambio en Educación, 3(1), 750-763. https://bit.ly/2Syx8Ee

Minedu adquirirá más de 840000 tablets para escolares y profesores. (18 de abril del 2020). Gestión. https://bit.ly/3ggtgRr

Ministerio de Cultura. (2017). Encuesta Nacional "Percepciones y Actitudes sobre Diversidad Cultural y Discriminación Étnico-Racial", 2017. https://bit.ly/3iDoaQR

Ministerio de Educación. (2020). Aprendo en casa. https://bit.ly/2TtCaCn 
Monge Acuña, V. (2015). La codificación en el método de investigación de la grounded theory o teoría fundamentada. Innovaciones Educativas, 22, 77-84. https://bit. ly/35kD5rn

Moyer-Gusé, E. (2010). El impacto de los medios de comunicación en la infancia: guía para padres y educadores. Editorial UOC. https://bit.ly/3iFmtCj

Mora-Jaureguialde, B. (2016). La radio universitaria como servicio público a la ciudadanía: el caso de Uniradio-UHU [Tesis de doctorado, Universidad de Huelva]. https://bit. ly/3vrvySk.

Narváez-Montoya, A. (2019). Comunicación educativa, educomunicación y educación mediática: una propuesta de investigación y formación desde un enfoque culturalista. Palabra Clave, 22(3), e22311. http://doi.org/10.5294/ pacla.2019.22.3.11

Niño, S., Castellanos, J. C., y Huerta, L. (2021). Implicaciones de la COVID-19 en la educación escolar; una revisión temprana de los artículos publicados en revistas académicas. Nóesis, 30(59), 38-58. https://doi.org/10.20983/noesis.2021.1.2

Ortiz Torres, E. A. (2012). La comunicación educativa y medios de enseñanza en la universalización. Editorial Universitaria. https://bit.ly/3gw6J12

Peñalosa, E., y Espinosa, M. (2011). Comunicación educativa. Revista Mexicana de Comunicación, 23(127), 21-23. https://bit.ly/2SujF0c

Ramírez, R. F., Manosalvas, M. I., y Cárdenas, O. S. (2019). Gender Stereotypes and Their Impact on the Women of Latin-America and Ecuador. Revista Espacios, 40(41), 29-33. https://bit.ly/3iEUvGQ

Repoll, J. (2010). Consumo y usos de la televisión en los mercados públicos de la ciudad de México. Comunicación y Sociedad, 14, 83-108. https://bit.ly/3rp0Ngp

Rojas, M. A. (2014). Retos a la educación peruana en el siglo xxI. REICE. Revista lberoamerica sobre Calidad, Eficacia y Cambio en Educación, 14(1), 101-114.

Resolución Ministerial 160-2020-MINEDU. Disponen el inicio del año escolar a través de la implementación de la estrategia denominada "Aprendo en casa", a partir del 6 de abril de 2020 y aprueban otras disposiciones. 1 de abril del 2020. Normas legales n. ${ }^{\circ}$ 15342. https://busquedas.elperuano.pe/download/ full/8-_LtQJj405AWmHLvQM8NU

Ruiz-Velasco, E. (Ed.). (2012). Tecnologías de la información y la comunicación para la innovación educativa. Universidad Nacional Autónoma de México, Posgrado en Pedagogía. 
Salud con Lupa. (18 de abril del 2020). La escuela rural: el reto de adaptar estrategias para un país diverso y desigual. https://bit.ly/2RPTS2i

Santa, R. (2021). El e-learning en educación primaria como consecuencia de la situación generada por el COVID-19: un estudio de caso. Revista Interuniversitaria de Investigación en Tecnología Educativa, 10, 121-136. https://doi.org/10.6018/ riite. 439831

Teixeira, M. M., Aquino, C. D., Silva, J. R., Medeiros, E. S., Santos, W. P., Santos, A. S., Souza, J. V., Gomes, A. A., Morais, C. A., Santos, A. C., y Alcântara, M. V. S. (2018). The Educational Technology of Radio in the European Union. 13th Iberian Conference on Information Systems and Technologies, Cáceres, España. https:// doi.org/10.23919/CISTI.2018.8399159

Velásquez, S., y Ruidiaz, K. (2021). La educación en tiempo de pandemia COVID-19: ¿realidad o ficción? Revista Cuidarte, 12(1), 1-4. http://dx.doi.org/10.15649/ cuidarte.1336

Velázquez, L. M. (2020). ¿Virtualizar o precarizar? Consecuencias de la pandemia. Cotidiano, Revista de la Realidad Mexicana, 35(221), 61-67. https://bit.ly/35j9TRm 
